\title{
Congruence of the current practices in Hymenoptera venom allergic patients in Poland with EAACI guidelines
}

Ewa Cichocka-Jarosz, Lavanya Diwakar², Piotr Brzyski³, Beata Tobiasz-Adamczyk³, Grzegorz Lis', Jacek J. Pietrzyk ${ }^{1}$

1Department of Pediatrics, Polish-American Children's Hospital, Jagiellonian University Medical College, Krakow, Poland

2Department of Allergy and Immunology, Heartlands Hospital, Birmingham, United Kingdom

3Department of Medical Sociology, Chair of Epidemiology and Preventive Medicine, Jagiellonian University Medical College, Krakow, Poland

Submitted: 4 September 2010

Accepted: 26 October 2010

Arch Med Sci 2011; 7, 5: 832-839

DOI: $10.5114 / a 0 m s .2011 .25558$

Copyright @ 2011 Termedia \& Banach

\begin{abstract}
Introduction: Venom immunotherapy (VIT) practice is the definitive treatment for patients with potentially fatal allergic reactions to Hymenoptera stings. The aim is assesing compliance of VIT practice in Poland with the current European Academy of Allergy and Clinical Immunology (EAACI) guidance.

Material and methods: A multicentre study was carried out using a structured questionnaire which was sent by post to all VIT practitioners in Poland. Some questionnaire items were altered, in comparison to original version by adding additional answer options or alowing multiple answer option. The response rate was $100 \%$. The obtained results were compared with the published EAACl guidelines.

Results: Twenty-six Polish centres took part in the survey. SSIgE and skin prick tests (SPT) are together used as the first line of investigation, whereas confirmatory intradermal tests (IDT) are applied in half of centres. Only a few centres measure baseline serum tryptase levels. The ultra-rush protocol is preferred. Antihistamine pre-medication is routinely practiced. A target dose equal to $100 \mu \mathrm{g}$ is used in most centres. A 6-week interval between booster doses is the most frequent. Five years is considered as an optimal VIT duration. Before the VIT completion, SSIgE is evaluated in fifty percent of centres, whereas sting challenge is considered by half of responders.

Conclusions: There are some differences between current practice in Poland and the EAACI recommendations, indicating areas requiring better compliance. Comparision between Poland and the United Kingdom revealed that health service organization and health care funding may play a major role in the provision of allergy services. This may affect the extent to which international guidance may be applied in individual countries. It is worth considering conducting the same survey in other European countries.
\end{abstract}

Key words: current practice, serum-specific lgE, skin tests, venom immunotherapy.

\section{Introduction}

European Academy of Allergy and Clinical Immunology (EAACI) recommendations summarize the results of studies evaluating the efficacy

\section{Corresponding author:}

Ewa Cichocka-Jarosz MD, PhD Department of Pediatrics Polish-American

Children's Hospital Jagiellonian University Medical College 265 Wielicka, 30-663 Krakow Poland

Phone: 481265820 11, ext. 1655

Fax: 48126584446

E-mail:mijarosz@cyfronet.pl 
and safety of venom allergy diagnosis and management [1, 2] (Table I). The adoption of these recommendations is dependent upon education, health system organization and cultural aspects unique to the country. Allergy to insect venom is a serious, potentially life-threatening condition. Venom immunotherapy (VIT) is the only treatment that has proven effective at decreasing the incidence and seriousness of subsequent sting reactions in affected individuals [1, 2]. Accordingly, patients who have experienced a systemic reaction to insect sting should be referred to an allergistimmunologist for diagnosis. The VIT is obligatorily indicated in patients with a history of a lifethreatening (cardiac or respiratory - grade 3 and 4 according to Mueller's classification) systemic reaction to Hymenoptera stings and demonstrable serum-specific IgE (SSIgE) antibodies to Hymenoptera venom [1-3]. In the case of IgEmediated grade 2 and grade 1 reaction, additional risk factors such as high exposure, or decreased quality of life arising from anxiety, are taken into consideration while establishing the indications for VIT $[2,4]$. There are some differences between the European and US approach to venom allergic patients. In the US, VIT introduction is more common in mild skin reactions, and trials of treatment in large local reactions are becoming increasingly popular [5]. Guidelines are of increasing importance in clinical practice. If corresponding recommendations are not followed, the quality of medical care will suffer. Ignoring recommendations from guidelines may also have legal consequences. Therefore the gap that exists between both national and international recommendations and clinical practice must be taken seriously. There are also Polish national guidelines concerning management of venom allergic patients, which strictly follow $\mathrm{EAACl}$ recommendations according to points from 2 to 6 and points from 18 to 24 presented in Table I, and do not refer to the other ones [6]. The first comprehensive audit of current practices in management of Hymenoptera venom allergic patients among the European Union countries was done in the United Kingdom [7].

The aim of our study was to estimate what level of congruence with EAACl guidelines is presented by current practice in management of Hymenoptera venom allergic patients in Poland.

\section{Material and methods}

In Poland, diagnostic investigation and management of venom allergic patients are exclusively conducted in 26 (18 for adults, 8 for children) university or large public health centres. A list of these centres is available on the Polish Allergology Society website (www.pta.pl). A previously published questionnaire was translated from
Table I. EAACI guidelines concerning diagnostic and therapeutic procedures towards venom allergic patients

\begin{tabular}{|c|c|}
\hline No* & Topic \\
\hline \multirow[t]{3}{*}{2.} & First line of investigation: \\
\hline & SPT \\
\hline & RAST \\
\hline \multirow[t]{2}{*}{4.} & Highest venom concentration used in SPT $[\mu \mathrm{g} / \mathrm{ml}]$ : \\
\hline & 100 \\
\hline 5. & IDT confirmatory in diagnosis \\
\hline \multirow[t]{2}{*}{6.} & Highest venom concentration used in IDT $[\mu \mathrm{g} / \mathrm{ml}]$ : \\
\hline & 1.0 \\
\hline \multirow[t]{3}{*}{7.} & $\begin{array}{l}\text { Treatment strategy in case of severe reaction and } \\
\text { uncertain culprit insect: }\end{array}$ \\
\hline & Both venoms \\
\hline & Discharge with Epipen \\
\hline
\end{tabular}

8. Baseline plasma tryptase in patients with history of severe SR

10. Strategy in systemic reaction with non-detectable venom slgE and normal baseline serum tryptase:

Discharge with Epipen

Follow up in 3 months

11. Strategy in systemic reaction with non-detectable venom slgE, elevated baseline serum tryptase:

Discharge with Epipen

Follow up in 3 months

16. Antihistamines in premedication of VIT: Troublesome local reactions

17. Grade 2-4 in Mueller's scale side effects during VIT: Accelerated regimen

18. Maximum time interval between the maintenance doses [weeks]:

4 within first year of treatment

6 within 2-5 years of treatment

8 over 5 years of treatment

19. Routine target maintenance dose $[\mu \mathrm{g} / \mathrm{ml}]$ : 100

20. $\operatorname{lgG}_{4}$ evaluation during or at the end of VIT: Not advisable

21. Optimal VIT duration [years]: 3-5

22. Sting challenge considered at the end of VIT: Advisable

23. slgE evaluation at the end of VIT: Advisable

24. Specific IgE detectable at the end of 3-5 years VIT period as indicator for VIT prolongation:

Advisable

In grade 4 reactions only

*Number in left column refers to number of item in the questionnaire 
English into Polish [6]. The translation process was done independently by two Polish native speakers with professional skills in English. Differences between the two versions were identified and eliminated during a consensus meeting. Then the questionnaire was retranslated and compared to the original version. Some adaptations, reflecting local differences in VIT practice, were required in the Polish version of the questionnaire as follows: A) question 2, the choice of both methods (RAST and SPT) performed simultaneously as a first line of investigation was allowed; B) questions 3 and 12 , the choice of other SPT extracts/treatment extracts, respectively, was added; C) questions 10 , 11,13 and 16, due to characteristics of VIT practices in Poland, were treated as multiple answer questions as opposed to multiple choice ones in the UK; D) question 14, information about previous experience with the accelerated protocol was reported as separated options; E) question 24, the answer option "other" was added. The questionnaire was sent to all centres by post. Answers were obtained from senior doctors directly responsible for management of venom allergic patients. The congruence of current practice with EAACI recommendations was expressed as the percentage of centres strictly following the recommended procedures.

\section{Results}

The audit response rate was $100 \%$ (in a few cases, a reminder by phone was necessary).

\section{Diagnostic tests}

As the first line of investigation, almost two thirds of Polish centres performed skin prick tests (SPT) with concentration $100 \mu \mathrm{g} / \mathrm{ml}$. Serum-specific IgE (SSIgE) application was common. Intradermal tests (IDT) with venom concentration equal to $1.0 \mu \mathrm{g} / \mathrm{ml}$ as a confirmatory procedure were performed in over one half of Polish centres.

\section{VIT PROTOCOL (including dosage, antihistamines, duration)}

The most common protocol of VIT incremental dose in Poland was ultra rush. Almost all the centres used the maintenance dose equal to $100 \mu \mathrm{g}$. One half of the centres practised a 6-week interval between the maintenance doses. Three to five years was the most frequent VIT duration, despite the severity of past sting reaction. In Polish practice, almost three fourths of the centres used premedication with antihistamines in all the treated patients. One third of the centres performed acceleration of the schedule and increasing the maintenance dose from $100 \mu \mathrm{g}$ to $200 \mu \mathrm{g}$ in case of grade 2-4 side effects during VIT.

\section{Management of non-evident cases}

Thirty-five percent of centres respected the strategy of providing self-injectable epinephrine upon discharge and performing follow-up in 6-12 months in a patient with SR, non-detectable SSIgE and normal baseline serum tryptase, while the same strategy was employed by only $27 \%$ of centres in patients with the same history and negative slgE, but elevated baseline serum tryptase.

\section{Additional tests (tryptase, $\operatorname{lgG}_{4}$, SSIgE before stopping therapy, sting challenge)}

Baseline serum tryptase at the beginning of treatment only in case of severe systemic reactions was performed in $40 \%$ of the centres where the estimation of this marker is available, which constitutes less than $20 \%$ of centres in Poland. At the end of VIT, almost one half of centres evaluated SSIgE; similarly, almost one half of them considered sting challenge. Specific $\operatorname{lgG}_{4}$ level both before treatment and before stopping VIT was rarely practised.

\section{Discussion}

The results obtained in this questionnaire survey allowed for description of current practice in management of the whole population of insect venom allergic patients (both adults and children) in Poland. We realize that the option of a selfcompleted questionnaire-based study limits the validity of obtained results. However, for objectivity of the data, answers to the questions were exclusively obtained from senior doctors directly responsible for management of venom allergic patients. They were all informed about the research purpose of the survey. On the other hand, we followed the same way of data collecting as in a British study, so comparisons to those data could be performed [7]. Previously only preliminary results of a multicentre (8 centres) study dedicated to current practices in Poland in management of venom allergic children were published [8]. The EAACI recommendations are strictly the same for adults and children, so only showing the current practices in all Polish allergy centres will reflect how the Polish health system allows for congruence of the current practices with the guidelines. It also indicates the topics which should be urgently improved. The total analysis is additionally justified, as centres for children closely cooperate with centres for adults, transferring patients at the age over 18 years for continuation of treatment. Finally, total results will be more representative for Poland against the European background, allowing them to be compared with British study results [7]. It may also encourage 
authors from other European countries to conduct similar studies, enabling further comparison (a panEuropean view).

\section{Comparison of current practice in Poland with $\mathrm{EAACl}$ recommendations}

There are some discrepancies between the current practice in Poland and the EAACl recommendations $[1,2]$. The results of our study are shown in Table II.

\section{Diagnostic tests}

Using both tests (SPT and SSIgE) together as the first line of investigation in Poland expresses their good availability and allows diagnostic duration to be shortened. It should be strongly emphasized that venom skin testing requires highly experienced staff to achieve highly repeatable results [9]. In patients with a negative SPT, it is therefore recommended to confirm this result in IDT. Positive results of IDT with venom concentration of $1 \mu \mathrm{g} / \mathrm{ml}$ confirm venom sensitization, while negative results exclude it. For this reason, some centres do not perform SPT. In our experience, positive results of SPT in children occur very seldom. A high percentage of centres evaluating SSIgE express good accessibility of the test, though its sensitivity is somewhat lower than that of IDT [10]. For providing the highest available sensitivity, the newer, third generation methods (ImmunoCAP, Immulite) are the most recommended [11, 12]. Both are in use in Poland. A "negative" result of skin testing could be due to insufficient sensitivity of tests or too long interval from the sting-induced reaction [12]. In patients with a history of severe SR reaction, confirmation of IgE-mediated reaction is important and allows for VIT commencement as a treatment of choice.

\section{VIT PROTOCOL}

The maintenance dose equal to $100 \mu \mathrm{g}$ was almost fully respected in Poland. Different schedules of treatment concerning the up-dosing phase required to reach the maintenance dose may last several weeks to months (conventional, clustered), a few days or even hours (rush or ultra rush protocol, respectively) $[2,13]$. The accelerated protocols predominate in Poland. The most popular aqueous venom extracts in Poland are Venomenhal (HALAllergy) and Pharmalgen (ALKAbello). Only a few centres use depot venom extract Alutard (ALKAbello). A 4-week interval between maintenance doses during the first year, 6 weeks within 2-5 years and 8 weeks over 5 years of VIT are recommended [2], though in the case of depot extracts, the interval from the beginning of maintenance doses might be up to 8 weeks. In the case of grade $2-4$ side effects during VIT, a high percentage of Polish centres accelerate the schedule and increase the maintenance dose from $100 \mu \mathrm{g}$ to $200 \mu \mathrm{g}$. In-patient management of these cases makes this procedure possible in Poland. According to our clinical observations, VIT-treated children well tolerating venom doses are protected at the early stage of treatment, which is consistent with the other data [14]. In Poland, pre-treatment with antihistamines was applied to all patients, probably as a result of well-known data of Polish origin on their advantageous effect on the immune response during VIT [15-17]. More clinical data supporting the use of antihistamine pre-treatment in all VIT patients are needed.

In the case of managing a patient with an unclear background of systemic reaction to sting, the original British questionnaire-reported time of a follow-up examination after 6-12 months is not in line with the EAACI recommendation of a followup visit 3 months after the event.

\section{Non-evident cases}

The important topic of safety indicates the low number of Polish centres providing self-injectable epinephrine upon discharge to patients after SR, with non-detectable SSIgE and uncertain insect stinging, normal or elevated baseline serum tryptase. It is a matter of question whether the emergency department (ED) staff supplies these patients with emergency kits immediately after severe SR, before referring them to a specialist [2], which is strongly recommended [18-20]. Epipen, Anapen and Fastject are well-known selfinjectable epinephrine specimens. Additionally, a low-cost product of Polish origin is also available on the market. Findings that only about one-third of patients received a prescription for selfinjectable epinephrine indicate an urgent need for education [20, 21]. Also, providing selfinjectable epinephrine immediately after reaction (ED) is recommended in the case of patients with SR and both honeybee and wasp venom positivity or an uncertain culprit insect. True double positivity to venoms creates a problem in the selection of venom for immunotherapy. True double positivity should be distinguished from the presence of cross reacting carbohydrate determinants of venoms [22]. When true double sensitivity has been confirmed, application of VIT with both venoms by a specialist is recommended. In the case of patients with a history of SR and undetectable IgE and normal baseline tryptase, follow-up within 3 months is recommended. It is justified in the case of severe SR, as negative skin tests after a recent sting anaphylaxis can occur during the refractory period of "anergy" for the first weeks after the event $[1,23]$. 
Table II. Characteristics of current diagnostic and therapeutic practice in patients with Hymenoptera venom allergy in Poland based on questionnaire study

\begin{tabular}{|c|c|c|c|}
\hline No & Question & $n$ & (\%) \\
\hline \multirow[t]{4}{*}{2.} & First line of investigation\#: & & \\
\hline & SPT & 0 & 0 \\
\hline & RAST & 8 & 31 \\
\hline & SPT + RAST & 18 & 69 \\
\hline \multirow[t]{8}{*}{3.} & Skin prick extract manufacturer: & & \\
\hline & ALK Pharmalgen & 4 & 15 \\
\hline & ALK commercial skin testing extract & 0 & 0 \\
\hline & HalAllergy & 15 & 58 \\
\hline & Venomil & 1 & 4 \\
\hline & Alutard ALK & 1 & 4 \\
\hline & ALK + HALAllergy & 5 & 19 \\
\hline & Other & 0 & 0 \\
\hline \multirow[t]{5}{*}{4.} & $\begin{array}{l}\text { Highest venom concentration used } \\
\text { in SPT }[\mu \mathrm{g} / \mathrm{ml}] \text { : }\end{array}$ & & \\
\hline & 10 & 2 & 8 \\
\hline & 100 & 22 & 84 \\
\hline & 200 & 2 & 8 \\
\hline & 300 & 0 & 0 \\
\hline 5. & IDT confirmatory in diagnosis & 23 & 88 \\
\hline \multirow[t]{5}{*}{6.} & $\begin{array}{l}\text { Highest venom concentration used } \\
\text { in IDT }[\mu \mathrm{g} / \mathrm{ml}] \text { : }\end{array}$ & & \\
\hline & 0.01 & 2 & 8 \\
\hline & 0.1 & 5 & 19 \\
\hline & 1.0 & 18 & 69 \\
\hline & 10 & 1 & 4 \\
\hline \multirow[t]{5}{*}{7.} & $\begin{array}{l}\text { Treatment strategy in case of severe } \\
\text { reaction and uncertain culprit insect: }\end{array}$ & & \\
\hline & Both venoms & 7 & 27 \\
\hline & Venom of higher IgE level & 7 & 27 \\
\hline & Discharge with Epipen & 1 & 4 \\
\hline & Other & 11 & 42 \\
\hline 8. & $\begin{array}{l}\text { Baseline plasma tryptase in patients } \\
\text { with history of SR }\end{array}$ & 10 & 39 \\
\hline \multirow[t]{3}{*}{9.} & Check tryptase in: & & \\
\hline & Systemic severe reaction & 4 & $40^{\&}$ \\
\hline & $\begin{array}{l}\text { All systemic reactions, irrespectively } \\
\text { of their severity }\end{array}$ & 6 & $60^{\&}$ \\
\hline \multirow[t]{5}{*}{10.} & $\begin{array}{l}\text { Strategy in systemic reaction with } \\
\text { non-detectable venom slgE } \\
\text { and normal baseline serum tryptase }\end{array}$ & & \\
\hline & Discharge with advice & 6 & 23 \\
\hline & Discharge with Epipen & 15 & 58 \\
\hline & Follow up in 6-12 months & 20 & 77 \\
\hline & Commence immunotherapy & 0 & 0 \\
\hline
\end{tabular}

\begin{tabular}{|llcc|}
\hline No & Question & $n$ & (\%) \\
\hline 11. & $\begin{array}{l}\text { Strategy in systemic reaction with } \\
\text { non-detectable venom slgE, elevated } \\
\text { baseline serum tryptase\#: }\end{array}$ & \\
\cline { 2 - 4 } & & \\
\hline Discharge with advice & 0 & 0 \\
\hline Discharge with Epipen & 11 & 42 \\
\hline Follow up in 6-12 months & 18 & 69 \\
\hline Commence immunotherapy & 1 & 4 \\
\hline
\end{tabular}

12. Immunotherapy extract manufacturer:

\begin{tabular}{lcc}
\hline ALK (Pharmalgen/Alutard) & 5 & 19 \\
\hline HALAllergy & 11 & 42 \\
\hline Both & 6 & 24 \\
\hline Other & 4 & 15
\end{tabular}

13. VIT protocol commonly applied\#:

\begin{tabular}{lcc}
\hline Conventional & 4 & 15 \\
\hline Clustered & 6 & 23 \\
\hline Rush & 5 & 19 \\
\hline Ultra rush & 15 & 58
\end{tabular}

14. Accelerated protocols ever applied\#:

\begin{tabular}{lll}
\hline Rush & 14 & 54 \\
\hline Ultra rush & 16 & 62
\end{tabular}

16. Antihistamines in premedication of VIT:

\begin{tabular}{lcc}
\hline Troublesome local reactions & 12 & 46 \\
\hline Systemic reactions & 7 & 27 \\
\hline Asthma or cardiorespiratory problems & 2 & 8 \\
\hline All patients & 19 & 73 \\
\hline Other & 0 & 0
\end{tabular}

17. Grade $2-4$ in Mueller's scale side effects during VIT:

\begin{tabular}{lcc}
\hline Discontinue treatment & 3 & 12 \\
\hline Accelerated regimen & 8 & 31 \\
\hline Persist with VIT as usual & 2 & 8 \\
\hline Other & 13 & 50
\end{tabular}

18. Maximum time interval between maintenance doses [weeks]:

\begin{tabular}{lcc|}
\hline 4 & 2 & 8 \\
\hline 6 & 13 & 50 \\
\hline 8 & 2 & 8 \\
\hline$\geq 12$ & 0 & 0 \\
\hline Other & 9 & 34 \\
\hline
\end{tabular}

19. Routine target maintenance dose $[\mu \mathrm{g} / \mathrm{ml}]$ :

\begin{tabular}{ccc}
\hline 100 & 24 & 92 \\
\hline 150 & 0 & 0 \\
\hline 200 & 2 & 8 \\
\hline
\end{tabular}


Table II. cont.

\begin{tabular}{|llcc|}
\hline No & Question & $n$ & (\%) \\
\hline 20. & $\begin{array}{l}\text { IgG } \\
\text { end ovaluation during or at the }\end{array}$ & 2 & 8 \\
\hline 21. & Optimal VIT duration [years]: & & \\
\cline { 2 - 4 } & 2 & 0 & 0 \\
\hline 3 & 1 & 4 \\
\hline 5 & 19 & 73 \\
\hline$>5$ & 4 & 15 \\
\hline & Other & 2 & 8 \\
\hline 22. & $\begin{array}{l}\text { Sting challenge considered at the } \\
\text { end of VIT }\end{array}$ & 12 & 46 \\
\hline
\end{tabular}

\begin{tabular}{|llcc|}
\hline No & Question & $n$ & (\%) \\
\hline 23. & slgE evaluation at the end of VIT & 12 & 46 \\
\hline 24. & $\begin{array}{l}\text { Specific IgE detectable at the end } \\
\text { of 3-5 years VIT period as indicator } \\
\text { for VIT prolongation: }\end{array}$ & & \\
\cline { 2 - 3 } & Yes & 5 & 19 \\
\hline $\begin{array}{l}\text { In grade 4 reactions only } \\
\text { No }\end{array}$ & 8 & 31 \\
\hline Other & 13 & 50 \\
\hline
\end{tabular}

\#Answer options altered in comparison to the original version, $n$ - number of centres which reported chosen category,

\& ratio of centres in relation to number of centres where estimation of serum tryptase was available

\section{Additional tests}

Baseline serum tryptase level expresses the whole body mast cell load and is a predictor of severe SR [24, 25]. It is recommended to be determined in all patients with such a history, though the frequency of its clinical application is still too low [1, 21]. In treated patients, VIT leads to a variety of specific immunological changes still being determined. It is unknown, however, which parameter shifts might indicate therapeutic success [26, 27]. The level of specific $\operatorname{lgG}_{4}$ primarily reflects exposure, and is not recommended in routine assessment [28]. Provocation with sting challenge is indicated in individual patients on a maintenance dose of VIT to identify those who are not yet protected $[29,30]$. Sting challenge before the end of VIT was considered in Poland, though formulation "considered" should not be understood as equal to "performed".

The results of specific lgE in monitoring the end of treatment often influenced the decision of VIT prolongation in Poland. The SSIgE evaluation at the end of VIT, though widely used in Poland, is helpful for making the decision on VIT cessation in the case of both skin and SSIgE negative results. Otherwise, the decision should be made individually. The VIT prolongation is justified in the case of a lifethreatening reaction in the past and SSIgE still detectable at the end of 3-5 years of treatment, which is a rather common practice in Poland.

\section{Comparison of current practice between Poland and the United Kingdom}

Since almost the same questionnaire was used in both Poland and the United Kingdom, we were able to make a comparison of VIT practice between these two regions.
The majority of differences in current practice seem to mirror the distinct organization of the national health system and economic aspects. In Poland, both the diagnosis and therapy in venom allergic patients are in-patient procedures, contrary to out-patient management in the United Kingdom. The inpatient-based service in Poland goes together with safety concerns (ICU accessibility) and may result in a higher percentage of centres performing IDT, accelerated regimes of regular treatment, accelerated treatment in case of systemic (grade 2-4) side effects during VIT introduction, considering sting challenge before the end of VIT, and longer duration of treatment [31]. In Poland, VIT procedures are usually performed either in university hospital units or large public health centres. It might be a matter of financial background that availability of evaluation baseline serum tryptase in Poland is much poorer, though if available, its clinical application is proper and concerns all patients with severe SR [1, 2]. In contrast, the outpatient-based service in the United Kingdom may imply a lower number of centres performing intradermal tests, considering insect-sting challenge before end of VIT, an almost exclusive use of the conventional schedule, as well as a shorter time of treatment. In both countries, the frequency of prescribing epinephrine for self-intervention was too low and this should be improved.

The presented study, based on an original unique British paper, allows us to estimate the congruence of a highly specialist procedure in Poland with EAACI guidelines and indicates the differences between two European countries. It was possible thanks to the application of the same tool and it might identify the necessary research fields, as well as indicating the topics requiring better education, and perhaps raise the question whether international guidelines might be 
respected in different countries to the same extent. It would be interesting to compare data from other European countries and, in the case of insufficient acceptance of guidelines, to analyse the reasons. Potential explanations are increasing economic pressure, insufficient medical education, poor patient compliance and the possibility that recommendations of guidelines cannot be implemented for practical reasons. The results might be a basis for a study of new guidelines and helpful in improvement of educational programmes. As it is a matter of safety and legal consequences, it is important to achieve a panEuropean consensus to obtain EAACI guidance and on how $\mathrm{EAACl}$ could probably do more to ensure homogeneity in this respect in Europe. Similarly, as in the other health promotion initiatives, in all settings it must be scientifically sound, culturally acceptable, and managerially feasible. Evidence by itself is not enough to generate action. Leadership is essential, this being "the capacity to influence others to work together to achieve a common purpose" [32, 33].

\section{Acknowledgments}

We declare no financial relationship with biotechnology/pharmaceutical manufacturers mentioned in this manuscript.

\section{References}

1. Bilo BM, Rueff F, Mosbech H, Bonifazi F, Oude-Elberink JN; Panel of Experts of EAACl Interest Group on Insect Venom Hypersensitivity. Diagnosis of Hymenoptera venom allergy. Allergy 2005; 60: 1339-49.

2. Bonifazi F, Jutel M, Bilo BM, Birnbaum J, Müller U; Panel of Experts of EAACI Interest Group on Insect Venom Hypersensitivity. Prevention and treatment of hymenoptera venom allergy: guidelines for clinical practice. Allergy 2005; 60: 1459.

3. Moffitt JE, Golden DBK, Reisman RE, et al. Stinging insect hypersensitivity: a practice parameter update. J Allergy Clin Immunol 2004; 114: 869-86.

4. Oude-Elberink JNG, de Monchy JGR, van der Heide S, Guyatt GH, Dubois AEJ. Venom immunotherapy improves health-related quality of life in patients allergic to yellow jacket venom. J Allergy Clin Immunol 2002; 110: 174-82.

5. Golden DBK, Kelly D, Hamilton RG, Craig TJ. Venom immunotherapy reduces large local reactions to insect stings. J Allergy Clin Immunol 2009; 123: 1386-90.

6. Jutel M, Kowalski ML, Kruszewski J, Rogala B, Bręborowicz A. Swoista immunoterapia alergenowi. Standardy w alergologii - część IV. Przegl Alergol 2005; 2: 43-9.

7. Diwakar L, Noorani S, Huissoon AP, Frew AJ, Krishna MT. Practice of venom immunotherapy in the United Kingdom: a national audit and review of literature. Clin Exp Allergy 2008; 38: 1651-8.

8. Cichocka-Jarosz E, Brzyski P, Lis G, et al. Diagnosis and venom specific immunotherapy in venom allergic children in Poland - how much the current practice follows the international guidelines. Przegl Lek 2010; 67: 1-5.
9. Corallino M, Nico A, Kourtis G, Caiaffa MF, Macchia L. Skin testing technique and precision in stinging insect allergy. J Clin Nursing 2007; 16: 1256-64.

10. Goldberg A. Variability of venom skin tests. Curr Opin Allergy Clin Immunol 2007; 7: 342-5.

11. Jeep S, Kircholf E, O'Connor A, Kunkel G. Comparison of Phadebas RAST with the PharmaciaCAP system for insect venom. Allergy 1992; 47: 212-7.

12. Hamilton RG, Adkinson FN. In vitro assays for the diagnosis of IgE-mediated disorders. J Allergy Clin Immunol 2004; 114: 213-25.

13. Sturm G, Kraanke B, Rudolph C, Aberer W. Rush hymenoptera venom immunotherapy: a safe and practical protocol for high-risk patients. J Allergy Clin Immunol 2002; 110: 928-33.

14. Gonzalez FJ, Almirall MC, Herrero AM, De la Torre F, Paris MB. Hymenoptera venom allergy: characteristics, tolerance and efficacy of immunotherapy in the paediatric population. Allergol Immunopathol 2009; 37: 111-5.

15. Jutel M, Watanabe T, Klunker S, et al. Histamine regulates T-cell and antibody responses by differential expression of $\mathrm{H} 1$ and $\mathrm{H} 2$ receptors. Nature 2001; 413: 420-5.

16. Müller U, Hari I, Berchtold E. Premedication with antihistamines may enhance efficacy of specific-allergen immunotherapy. J Allergy Clin Immunol 2001; 107: 81-6.

17. Reimers A, Hari Y, Müller U. Reduction of side-effects from ultrarush immunotherapy with honeybee venom by pretreatment with fexofenadine: a double-blind, placebocontrolled trial. Allergy 2000; 55: 484-8.

18. Tse Y, Rylance G. Emergency management of anaphylaxis in children and young people: new guidance from the Resuscitation Council (UK). Arch Dis Child Ed Pract 2009; 94: 97-101.

19. Muraro A, Roberts G, Clark A, et al. EAACl Task Force on Anaphylaxis in Children. The management of anaphylaxis in childhood. Allergy 2007; 62: 857-71.

20. Simons FER, Frew AJ, Ansotegui IJ, et al. Risk assessment anaphylaxis current and future approaches. J Allergy Clin Immunol 2007; 120: 2-24.

21. Simons FER. Anaphylaxis: recent advances in assessment and treatment. J Allergy Clin Immunol 2009; 124: 625-36.

22. Müller UR, Johansen N, Petersen AB, Fromberg-Nielsen J, Haeberli G. Hymenoptera venom allergy: analysis of double positivity to honey bee and Vespula venom by estimation of IgE antibodies to species-specific major allergens Api m1 and Ves v5. Allergy 2009; 64: 543-8.

23. Przybilla B, Ruëff F. Hymenoptera venom allergy. J Dtsch Dermatol Ges 2010; 8: 114-27.

24. Ruëff F, Przybilla B, Müller U, Mosbech H. The sting challenge test in hymenoptera venom allergy. Position paper of the Subcommittee on insect venom allergy of the European Academy of Allergology and Clinical Immunology. Allergy 1996; 51: 216-25.

25. Kucharewicz I, Bodzenta-Lukaszyk A. Szymanski W, Mroczko B, Szmitkowski N. Basal serum tryptase level correlates with severity of hymenoptera sting and age. J Investig Allergol Clin Immunol 2007; 17: 65-9.

26. Brasch J, Maidusch T. Immunotherapy with wasp venom is a accompanied by wide-ranging immune responses that need further exploration. Acta Derm Venerol 2009; 89: 466-9.

27. Pereira-Santos MC, Babtista AP, Melo A, et al. Expansion of circulating foxp3+CD25brightCD4+ T cells during specific venom immunotherapy. Clin Exp Allergy 2007; 38: 291-7.

28. Ewan PW, Deighton J, Wilson AB, Lachman PJ. Venomspecific IgG antibodies in bee and wasp allergy: lack of 
correlation with protection from stings. Clin Exp Allergy 1993; 23: 647-60.

29. Ruëff F, Przybilla B, Biló MB, et al. Predictors of severe systemic anaphylactic reactions to patients with hymenoptera venom allergy: importance of baseline serum tryptase - a study of the European Academy of Allergology and Clinical Immunology Interest Group on Insect Venom Hypersensitivity. J Allergy Clin Immunol 2009; 124: 1047-54.

30. Reisman RE. Duration of venom immunotherapy: relationship to the severity of symptoms of initial insect sting anaphylaxis. J Allergy Clin Immunol 1993; 92: 831-6.

31. Haugaart L, Nooregaard OFH, Dahl R. In-hospital sting challenges insect venom-allergic patients sting challenges in insect venom-allergic patients after stopping venom immunotherapy. J Allergy Clin Immunol 1991; 87: 699-702.

32. White F, Nanan D. Community health case studies selected from developing and developed countries common principles for moving from evidence to action Arch Med Sci 2008; 4: 358-63

33. Gasparyan AY, Banach M. A medium science communication in our times. Arch Med Sci 2009; 5: 1. 